\title{
Results with Expanded Endonasal Resection of Skull Base Meningiomas: Technical Nuances and Approach Selection Based on an Early Experience
}

\author{
Caroline HAYHURST ${ }^{1}$, Michael E. SUGHRUE², Pankaj A. GORE ${ }^{3}$, Phillip A. BONNEY², Joshua D. BURKS², \\ Charles $\mathrm{TEO}^{3}$ \\ ${ }^{1}$ University Hospital of Wales, Department of Neurosurgery, Cardiff, United Kingdom \\ 'University of Oklahoma Health Sciences Center, Comprehensive Brain Tumor Center, Oklahoma City, OK, USA \\ ${ }^{3}$ Prince of Wales Private Hospital, The Centre for Minimally Invasive Neurosurgery, Randwick, New South Wales, Australia
}

\section{ABSTRACT}

AIM: Reconstruction technique advances have created renewed enthusiasm for the expanded endonasal approach (EEA). However, as with any new technique, early experiences inevitably lead to more selective use of these techniques. We reviewed our experience of the expanded endonasal endoscopic approach for skull base meningiomas and place it in context of the literature.

MATERIAL and METHODS: We performed retrospective review of all endonasal cases performed at our center for histologically proven meningioma. Tumor locations in 26 patients included the olfactory groove $(n=9)$, tuberculum sellae $(n=7)$, optic nerve sheath $(n=1)$, planum sphenoidale $(n=2)$, clival $(n=1)$ petroclival $(n=3)$, cavernous sinus $(n=2)$ and extensive pan-basal meningioma $(n=1)$.

RESULTS: The median follow-up was 38.6 months. Excluding 3 patients with tumors found incidentally, pre-operative symptoms improved in 14 of $23(61 \%)$, were the same in 8 of $23(35 \%)$ and worsened in one of 23 patients (4\%) at time of last follow-up. Of all 26 patients, 16 (62\%) had complete macroscopic resection of their tumor, 5 (19\%) underwent at least $90 \%$ resection, and 5 (19\%) underwent subtotal resection. There were two neurological complications and one cerebrospinal fluid leak.

CONCLUSION: This study presents outcomes of patients treated with endonasal endoscopic meningioma surgery. We believe that very low rates of morbidity can be achieved in carefully selected patients, thus avoiding brain manipulation.

KEYWORDS: Endoscopy, Expanded endonasal, Minimally invasive, Meningioma, Skull base

\section{INTRODUCTION}

$\mathrm{E}$ xperience with endonasal transsphenoidal pituitary procedures has taught us that whenever anatomically feasible, surgery through the nose is better tolerated than transcranial surgery. Initial clinical reports of the utility of the endonasal approach for midline skull base meningiomas were published more than a decade ago $(14,15,18)$. However, the widespread acceptance of the expanded endonasal route has only been made possible with advances in skull base reconstruction. With the introduction of multilayered closure and a vascularized mucosal flap reconstruction, rates of cerebrospinal fluid (CSF) leak have dropped to between $3-5 \%(8,11$, $12,17)$, which is comparable to the reported $3.9 \%$ leak rate following standard microscopic transsphenoidal pituitary surgery (3).

These advancements in reconstruction techniques have led to renewed enthusiasm for the expanded endonasal approach (EEA) at many centers. However, while the endonasal approach yields some advantages over transcranial surgery, it is not always possible or even advisable to attempt to resect all 
meningiomas endonasally. How to select between these options involves an understanding of anatomy and experience. In this manuscript, we review our experience of the expanded endonasal endoscopic approach for skull base meningiomas and place it in the context of the pre-existing literature.

\section{MATERIAL and METHODS}

\section{Patient Population}

The current study is a review based on all endonasal cases performed at our institution between 1995 and 2010; 26 cases performed for histologically proven meningioma were identified and form the study cohort. Twenty-one patients (81\%) were female and the median age at operation was 50 years (range 28-76 years). Table I demonstrates the patient characteristics. No patients had undergone previous surgery or radiotherapy. All patients underwent post-operative magnetic resonance imaging (MRI) at 6 weeks, 6 months, and then yearly thereafter. The extent of resection was determined based on the first post-operative imaging. This study was performed with the approval and following local institutional guidelines for human research.

\section{Case Selection Paradigm}

While our decision-making generally evolved throughout the course of this series (described in detail below), we generally considered the following factors when deciding whether or not to use an expanded endonasal approach: (1) the surgical goal, either gross total resection or subtotal resection; (2) the age of the patient; (3) the presence of vascular encasement, which generally contraindicated endonasal surgery; (4) the presence of a dural tail extending laterally beyond the limits of the EEA bony exposure, which generally reduced our enthusiasm for endonasal approaches when the goal was gross total resection; and (5) previous surgery or radiotherapy, which similarly decreased our enthusiasm for endonasal surgery. Vascular encasement is our only absolute contraindication to EEA, where a complete resection is the goal. In general, we have a low threshold for considering a minimally invasive transcranial approach or a combined/staged EEA and transcranial procedure to achieve the best extent of resection with the least morbidity.

\section{Surgical Technique}

All cases were performed jointly by a neurosurgeon and a rhinologist. The expanded endonasal approaches to relevant portions of the cranial base have been described extensively $(4,5,7,10,20)$, and some nuances of our approach are described below.

\section{Parasellar Tumors}

The approach to the sphenoid sinus is the foundation of most endonasal approaches. To allow for sufficient working room the rostrum of the sphenoid should be reduced completely to the level of the sphenoid sinus floor. Bony decompression is carried out anterior to the sella exposing the superior intercavernous sinus and the dura underlying the tuberculum sellae and posterior planum sphenoidale. At the tuberculum sellae the width of dural opening is limited postero-inferiorly by the flanking cavernous carotid segments and anterosuperiorly by the bony optic canals.

\section{Anterior Fossa Tumors}

Exposure of the planum sphenoidale requires entry into the posterior ethmoidal air cells. The posterior ethmoidal septations are reduced to the level of the skull base with the high speed drill. Depending on the size of the meningioma, the cribriform plate can be accessed either by an anterior extension of the transplanum approach or by a direct approach through the ethmoidal air cells. The anterior ethmoidal septations are reduced to the level of the skull base and the superior aspect of the nasal septum is resected. This provides a single working cavity bounded laterally by the lamina papyracea. Focal elevation of the lamina papyracea in the region of the anterior and posterior ethmoidal arteries allows isolation and sacrifice of these tumor feeders. The cribriform plate and crista galli are then drilled to access the dura underlying the tumor.

\section{Cavernous Sinus Tumors}

Exposure of the cavernous sinus is achieved by a retro-carotid route. We do not use neuromonitoring for these cases. A very well aerated sphenoid sinus may permit ready access to the most medial portion of the cavernous sinus. Poorly aerated sinuses require drilling of the upper clivus using anatomical landmarks, frameless stereotactic guidance and micro-Doppler for identification and preservation of the intracavernous carotid artery. After identifying the location of the carotid artery, we incise the ventral cavernous dura medial to this site to achieve access to the medial cavernous sinus. Venous bleeding is controlled with patient positioning and thrombostatic agents. Tumor is removed using suction or ultrasonic aspiratory devices, and after removing tumor from the medial cavernous sinus, angled endoscopes and angled suctions are used to work lateral to the cavernous carotid artery by gently passing the angled instruments behind the artery. It is important to note that maneuvers lateral to the cavernous carotid are quite challenging even with experience, and these maneuvers may not be safe in less experienced hands.

\section{Clival/Petroclival Tumors}

Petroclival and clival exposure is accomplished by removing the vomer and floor of the sphenoid sinus completely. The course of the petrous carotid defines the extent of the clivus that can safely be drilled. Rostrally, between the paraclival vertical segments of the petrous carotid, bony decompression should be confined to the midline. Inferior to the horizontal petrous carotid, lateral drilling is permissible if necessary. The vidian nerve and artery travel in the vidian canal and join the carotid at the genu between the horizontal and vertical petrous segments, serving as an important landmark during drilling. Frameless stereotactic guidance is essential in defining the extent of bony drilling necessary.

We prefer a midline incision of the clival dura to avoid injury to the abducens nerve as it enters Dorello's canal. To access the petroclival region, the dural opening can be extended laterally so the overall incision has a "T-shaped" configuration. Angled 
Table I: Patient Characteristics

\begin{tabular}{|c|c|c|c|c|c|c|c|}
\hline Pt \# & $\begin{array}{c}\text { Age } \\
\text { (years) }\end{array}$ & Gende & & $\begin{array}{l}\text { Goal of } \\
\text { Surgery }\end{array}$ & EOR & $\begin{array}{c}\text { Surgical } \\
\text { Complication }\end{array}$ & $\begin{array}{l}\text { Neurological } \\
\text { Complication }\end{array}$ \\
\hline \multicolumn{8}{|c|}{ Parasellar } \\
\hline 1 & 55 & $\mathrm{~F}$ & Tuberculum Sellae & GTR & STR & No & No \\
\hline 2 & 33 & $\mathrm{~F}$ & Tuberculum Sellae & GTR & STR & No & No \\
\hline 3 & 49 & $\mathrm{M}$ & Tuberculum Sellae & GTR & GTR & No & No \\
\hline 4 & 44 & $\mathrm{~F}$ & Tuberculum Sellae & GTR & NTR & No & No \\
\hline 5 & 65 & $\mathrm{~F}$ & Tuberculum Sellae & GTR & GTR & No & No \\
\hline 6 & 47 & $\mathrm{M}$ & Tuberculum Sellae & GTR & GTR & No & Frontal Infarct, abulia \\
\hline 7 & 29 & M & Tuberculum Sellae & GTR & GTR & No & No \\
\hline 8 & 45 & $\mathrm{~F}$ & Optic Canal & GTR & STR & No & No \\
\hline \multicolumn{8}{|c|}{ Anterior Fossa } \\
\hline 9 & 60 & $\mathrm{~F}$ & Olfactory Groove & GTR & GTR & No & No \\
\hline 10 & 37 & $\mathrm{~F}$ & Olfactory Groove & GTR & GTR & No & No \\
\hline 11 & 38 & $\mathrm{~F}$ & Olfactory Groove & GTR & GTR & No & No \\
\hline 12 & 50 & $\mathrm{~F}$ & Olfactory Groove & GTR & GTR & No & No \\
\hline 13 & 62 & $\mathrm{~F}$ & Olfactory Groove & GTR & GTR & No & No \\
\hline 14 & 76 & M & Olfactory Groove & GTR & GTR & No & No \\
\hline 15 & 40 & $\mathrm{~F}$ & Olfactory Groove & GTR & GTR & No & No \\
\hline 16 & 30 & $\mathrm{~F}$ & Olfactory Groove & GTR & GTR & Meningitis & No \\
\hline 17 & 59 & $\mathrm{~F}$ & Olfactory Groove & NTR & NTR & No & No \\
\hline 18 & 50 & $\mathrm{~F}$ & Planum Sphenoidale & GTR & GTR & No & No \\
\hline 19 & 51 & $\mathrm{~F}$ & Planum Sphenoidale & GTR & GTR & No & No \\
\hline \multicolumn{8}{|c|}{ Cavernous Sinus } \\
\hline 20 & 70 & $\mathrm{~F}$ & Cavernous sinus & NTR & NTR & No & No \\
\hline 21 & 28 & $\mathrm{M}$ & Cavernous sinus & GTR & GTR & No & No \\
\hline \multicolumn{8}{|c|}{$\underline{\text { Clival/Petroclival }}$} \\
\hline 22 & 54 & $\mathrm{~F}$ & Petroclival & STR & NTR & CSF leak & Diplopia \\
\hline 23 & 67 & $\mathrm{~F}$ & Petroclival & STR & STR & No & No \\
\hline 24 & 67 & $\mathrm{~F}$ & Petroclival & STR & NTR & No & No \\
\hline 25 & 53 & $\mathrm{~F}$ & Pan-skull base & STR & STR & No & No \\
\hline 26 & 34 & $\mathrm{~F}$ & Clival & GTR & GTR & No & No \\
\hline
\end{tabular}

GTR: Gross total resection, STR: Subtotal resection, NTR: Near total resection, CSF: Cerebrospinal fluid, pt: Patient, EOR: Extent of resection, M: Male, F: Female. 
endoscopes and instruments are particularly useful to access the petroclival junction and even the adjacent posterior cavernous sinus.

\section{Tumor Resection}

The principles for endonasal resection of meningiomas are not dissimilar to standard microsurgical principles: early devascularization, piecemeal tumor debulking, a combination of sharp and blunt dissection of the tumor capsule off surrounding structures, minimal traction, and where possible, preservation of arachnoid planes. The 0 and 30 degree endoscopes are used in all cases.

\section{Skull Base Reconstruction}

We place an oversized free fat graft within the defect so it assumes an hourglass shape with a bulbous intra- and extradural component ('snowman' configuration) held in place by the narrow dural waist (Figure $1 \mathrm{~A}-\mathrm{C}$ ). Fibrin glue is applied over the fat graft and the sphenoid sinus is packed with Gelfoam. The repair is maintained with a 14 French Foley catheter placed through the nostril and into the nasopharynx under endoscopic guidance so that when the balloon is inflated, it applies direct tamponade over the entire construct. No lumbar drains are used; however, while the patient is under anesthesia after the resection, an 18-gauge spinal needle is used to perform a lumbar puncture in a deliberate attempt to create a temporary spinal leak. To date, we have not noted any herniation or intracranial hypotension complications with this technique. The Foley catheter is removed 48 hours after surgery. Our current technique also employs the vascularized nasoseptal flap as described by Hadad et al. (11).

\section{Data Collection}

Worsening in visual function was defined as any new visual field cut, or any significant decline in visual acuity post-operatively. Neurologic deficits were compared to pre-operative baseline, and the worsening of a pre-existing deficit, or the presence of a new neurologic deficit, were both considered to be neurologic complications. The term surgical complication includes any CSF leak, meningitis, significant nasal morbidity requiring more than routine nasal care and debridement. Clinical data were collected from patient records and telephone interviews. All clinical assessments were performed by a neurosurgeon. We routinely performed T1 post-gadolinium fat saturated images with $2.5 \mathrm{~mm}$ cuts at 6 weeks post-operatively, and used the radiologist's report as the assessment of extent of resection. We have historically had an endocrinologist see all of our parasellar tumors pre and post-operatively and there was no noted effect on endocrine function in these cases. For purposes of analysis, planum sphenoidale tumors were
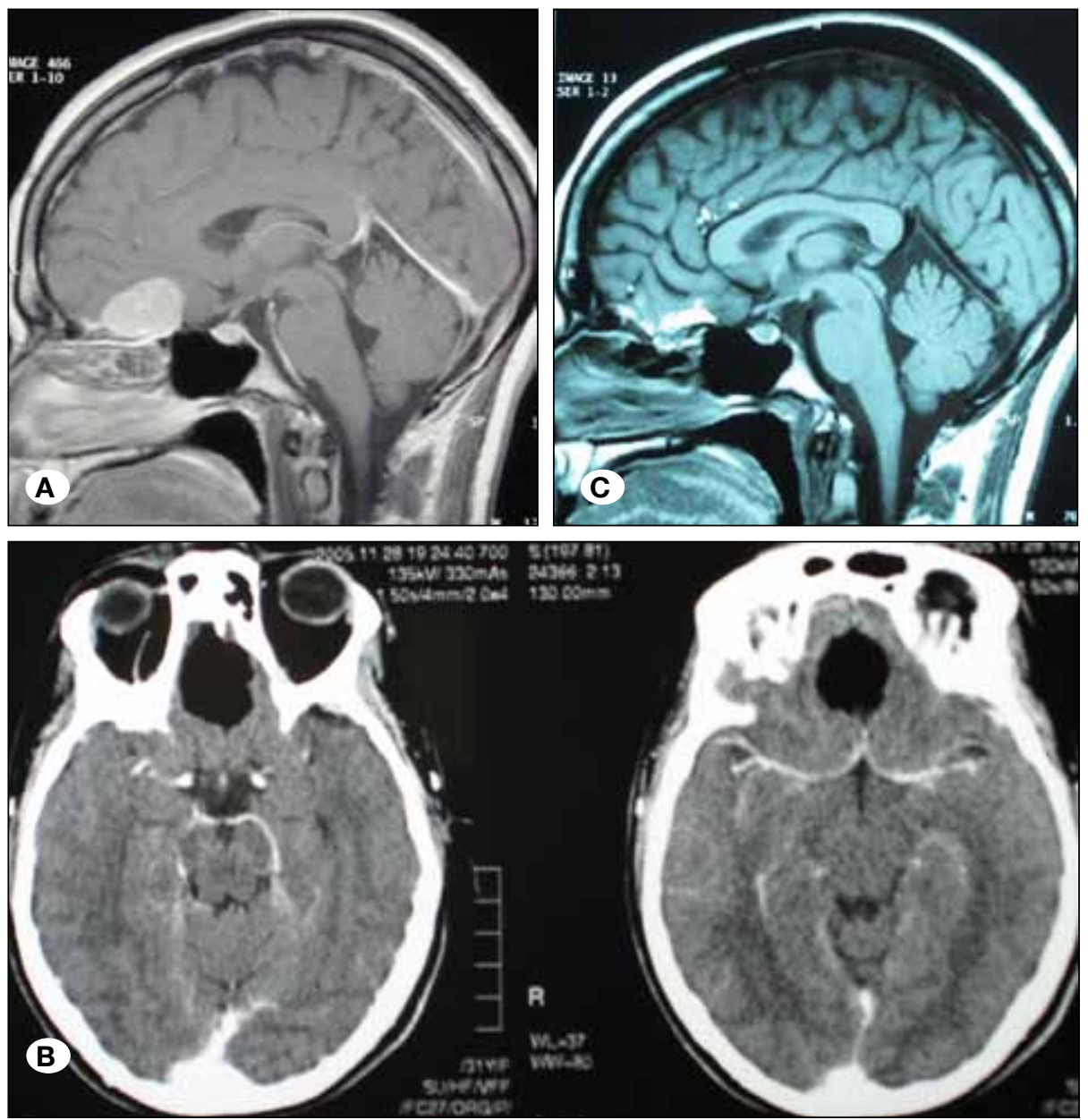

Figure 1: A) Preoperative sagittal T1 MRI with contrast demonstrates an olfactory groove meningioma.

B) Immediate postoperative axial CT with contrast demonstrates complete resection of the tumor and fat autograft occupying the tumor bed.

C) 6-month sagittal T1 MRI

demonstrates progressive flattening of the fat graft. 
distinguished from tuberculum sella meningiomas based on the site of the majority of the dural origin of the tumor.

\section{- RESULTS}

\section{Overall Results}

The median follow-up for the entire cohort is 38.6 months (range $12-60$ months). None of the 26 patients were lost to follow-up. The median diameter of the tumor was 25 $\mathrm{mm}$ (range $8-55 \mathrm{~mm}$ ). All patients had WHO grade 1 meningiomas. Excluding 3 patients with tumors found incidentally, pre-operative symptoms improved in 14 of 23 $(61 \%)$, were the same in 8 of $23(35 \%)$ and were worse in one of 23 patients at the time of last follow-up (Table I). No new neurologic symptoms or complications occurred in the patients with incidental tumors. Sixteen patients (62\%) had a complete macroscopic resection of the tumor. An additional 5 patients (19\%) underwent at least a $90 \%$ resection, leaving tumor where it was adherent to vessels. Five patients (19\%) underwent subtotal resection.

One patient (3.8\%) had a post-operative CSF leak for which endonasal re-exploration was undertaken 7 days after initial surgery. However, in the last 2 years of the series, following introduction of modified skull base reconstruction techniqueseither 'snowman' fat graft (10 patients) or nasoseptal flap (in 6 patients) - no patient has suffered CSF leak.

\section{Parasellar Tumors}

Eight patients in our series underwent EEA for resection of a parasellar meningioma. All 8 cases of tuberculum sella/optic canal meningiomas had invasion of the optic canal, and thus the canals were opened in all cases. Gross total resection was obtained in 4 patients (50\%), near total (> 90\% resection) was obtained in 1 patient (12.5\%), and subtotal resection was obtained in 3 patients (37.5\%). Incomplete resection in these cases was performed due to adhesion of the tumor to the optic nerve sheath (1 case), and the carotid or other vessels in the rest. Four patients had normal preoperative vision and none of these patients experienced loss of visual acuity postoperatively. Four patients presented with visual field defects, which remained unchanged after surgery. Thus, there were no changes in visual acuity in these patients from preoperative function.

There were no CSF leaks in these patients. One patient developed a symptomatic left frontal infarct immediately following surgery for a tuberculum sella meningioma, likely secondary to inadvertent sacrifice of a branch of the anterior cerebral artery (Figure 2A, B).

\section{Anterior Fossa Tumors}

There were 11 patients in our series who underwent an EEA approach for a meningioma of the anterior skull base (olfactory groove or planum sphenoidale). Gross total resection (GTR) was obtained in $10 / 11$ patients $(91 \%)$, with near total resection being intentionally performed in an attempt to preserve smell in one patient who was not anosmic. There were no documented CSF leaks in these patients; however, one patient did develop meningitis without documented CSF leak, and this was successfully treated with antibiotics.

\section{Cavernous Sinus Tumors}

Two patients underwent EEA for removal of meningiomas from the medial cavernous sinus. One was gross totally resected, and the other near totally resected in an attempt to preserve cranial nerve function. There were no complications in this cohort.

\section{Clival/Petroclival Tumors}

There were 5 patients in this series undergoing EEA for posterior fossa meningiomas (3 petroclival, 1 clival, and 1 extensive pan-skull base meningioma). Gross total resection was obtained in one case (20\%) with the rest undergoing near total resection (two cases; 40\%), or subtotal resection (two cases; $40 \%$ ). Near total resections were performed in cases
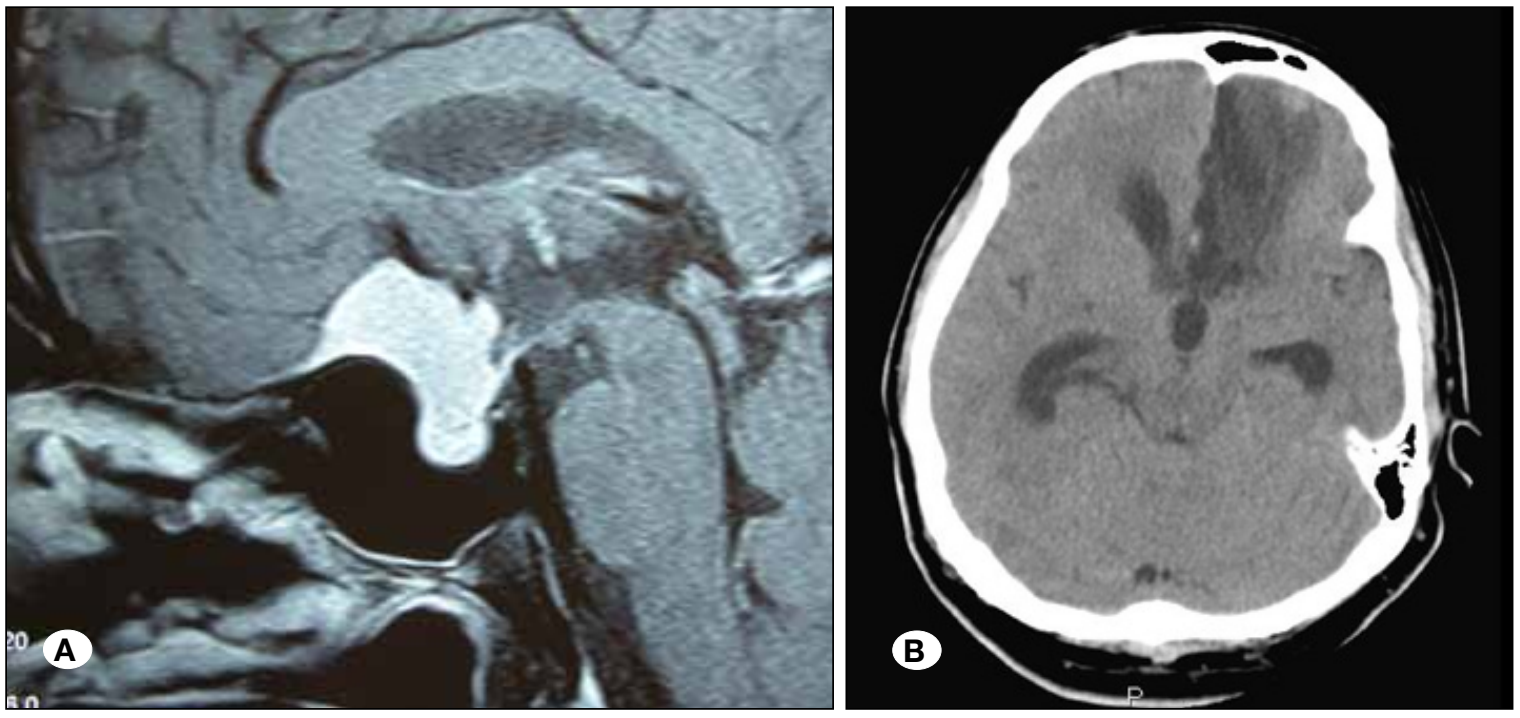

Figure 2:

A) Preoperative sagittal T1 MRI with contrast demonstrates a tuberculum sella meningioma with intimate relationship to the anterior cerebral artery complex. B) Immediate post-operative axial CT with left frontal infarct. 
when a small piece adherent to cranial nerves needed to be left. One case was subtotally resected, with the remnant being entirely left within the cavernous sinus. The pan-skull base tumor was subtotally resected due to its dense fibrous adhesions to multiple nerves and vessels. One patient had a temporary diplopia which improved in follow up. This same patient experienced a CSF leak that required a return to the operating room. Otherwise, there were no complications in this cohort (Figure 3A-E).

\section{DISCUSSION}

There are presently a number of valid surgical and radiotherapeutic approaches to treating meningiomas of the cranial base. The future of skull base tumor surgery is developing a scientific, hypothesis-driven method for determining which approach or combination of approaches or techniques is best in a specific situation, and this will require site- and anatomic-specific data regarding the risks and benefits of given approaches.

Endonasal endoscopic surgery is a skill set which can only be obtained with cadaveric dissection and progressive experience. We have shown that excellent results with the EEA can be achieved if used on carefully selected patients, and if reasonable function sparing compromises are made during the tumor resection.

\section{Parasellar Meningiomas}

The role of the endonasal approaches in these cases is a controversial topic, with valid arguments for both endonasal and transcranial approaches. Endonasal surgery allows the surgeon to easily unroof the medial optic canal, where tuberculum meningiomas classically invade the canal and compress the optic nerve. Also, retrochiasmatic tumor portions are much easier to visualize and remove from below without excessive manipulation of the optic apparatus. Transcranial approaches benefit from a greater range of working angles, facilitating the gentle bimanual dissection needed to preserve the critical chiasmatic vessels, which are often involved with the tumor. Such microdissection is possible -albeit difficultwith endonasal surgery. Anterolateral approaches provide excellent ability to identify these vessels earlier in the resection than is usually possible from below.

Presently, we select the endonasal approach for parasellar meningiomas which are mostly midline and that have a well aerated sphenoid sinus. If the pre-operative goal of surgery is curative total resection and the tumor does not involve the cavernous sinus and is not intimately related to the basilar artery and its perforators, then we feel a complete excision is likely and as such a transcranial route is chosen. If the aim of surgery is neurovascular decompression (i.e., optic nerves or chiasm, brain stem, third ventricle, etc.) but not complete resection, we then choose the EEA.

There have been several series published with data on purely endoscopic approaches to tuberculum sellae meningiomas. In these series, complete resection rates have upwards of $85 \%$, with visual improvement in approximately $85 \%$ and CSF leak rates of approximately $20 \%(10,13,19)$.

\section{Anterior Fossa Meningiomas}

The goal for surgical resection of most planum sphenoidale and olfactory groove meningiomas is Simpson grade 1 resection. This is a relatively high standard for endonasal surgery to meet; however, in our series gross total resection was achieved in $91 \%$ of cases. In the only case where it was not achieved, the result would have been similar in a transcranial approach. Morbidity was acceptable in this cohort, and likely does not differ from a transcranial cohort. Our rates of complete resection in this region are higher than those previously reported in the literature at approximately $75 \%(10,23)$. Our rates are likely the result of case selection, and learning from others.

Cerebrovascular injury can result, even in experienced hands, with endonasal resection of meningiomas with vascular involvement $(6,10)$. Early in our series, one patient experienced permanent neurological deficit following resection of a tuberculum sellae meningioma. During the case minimal traction on the tumor capsule resulted in bleeding from the dome of the tumor which was easily controlled with thrombostatic agents and the case proceeded without further adverse events. However, the patient exhibited persistent short-term memory loss post-operatively with a left frontal infarct on imaging. The preoperative imaging had shown an intimate relationship of the anterior cerebral artery complex to the superior surface of the tumor, but not frank encasement. We now view vascular involvement as an absolute contraindication to the EEA and only offer this approach when a clear 'cortical cuff' separating the tumor from vessels exists, generally preferring to tackle these through a supraorbital keyhole approach to achieve gross total resection $(16,21)$.

It is important to note that patients should be warned that anosmia is an almost certain event after the transcribriform approach. However we have preserved smell in some patients with a unilateral approach.

\section{Cavernous Sinus Tumors}

Recent years have seen a decrease in enthusiasm for aggressive forays into the cavernous sinus to remove meningiomas. Stereotactic radiosurgery has generally been shown to yield lower rates of cranial neuropathy, while achieving tumor control rates that are comparable to microsurgical gross total resection (22). Radiographic gross total resection of cavernous sinus meningiomas has been documented by numerous groups as being feasible. Whether radiographic GTR truly corresponds to absence of microscopic disease is controversial, and even gross totally-resected tumors can recur in these cases. However, our results with these tumors demonstrate that meningioma surgery in the medial cavernous sinus can be performed safely.

Several groups have reported results with endoscopic resection of cavernous sinus tumors, though mostly focusing on pituitary adenomas $(2,9)$. In our series, we had 1 gross-total resection and 1 near-total resection with no complications. Regarding the safety of these operations, neuromonitoring of relevant cavernous sinus cranial nerves may be helpful in reducing the risk of injury. However, more experience with 
these techniques is needed to clarify the benefits of this modality.

Ultimately, it remains to be seen whether aggressive surgery improves the natural history of these tumors. It is known that the medial cavernous sinus approached transsphenoidally is a safe working space, as the cranial nerves are lateral to the carotid at this point (1). Careful identification of the carotid is critical in these cases, as these tumors will typically encase this vessel. Again, we emphasize that extending beyond the carotid is a dangerous maneuver and is not recommended as standard practice. Currently, we select endonasal, endoscopic surgery for cavernous sinus surgery when imaging clearly demonstrates tumor medial to the nerves and where the goal of surgery is not necessarily complete excision.

\section{Clival/Petroclival Meningiomas}

These tumors have long been recognized challenging lesions to consistently achieve good outcomes and complete resections. In a series of 7 patients with either petroclival meningiomas (2 patients) or parasellar meningiomas with petroclival extension (5 patients), mean resection was $70 \%$ with no gross-total resections (10). In our series, gross-total resection was achieved in 1 cases and subtotal resection was achieved in the remaining 4.

The EEA transclival route to this region represents a promising option for addressing the medial portion of these tumors, as it devascularizes the tumor, and allows a direct approach to the medial petroclival junction and clivus with the cranial nerves largely out of the working trajectory. These approaches allow the brain stem to be decompressed, and the basilar circulation to be identified early in the resection. In our experience, grosstotal resection is not advisable for many of these lesions, and treatment goals must be established with the patient prior to surgery.
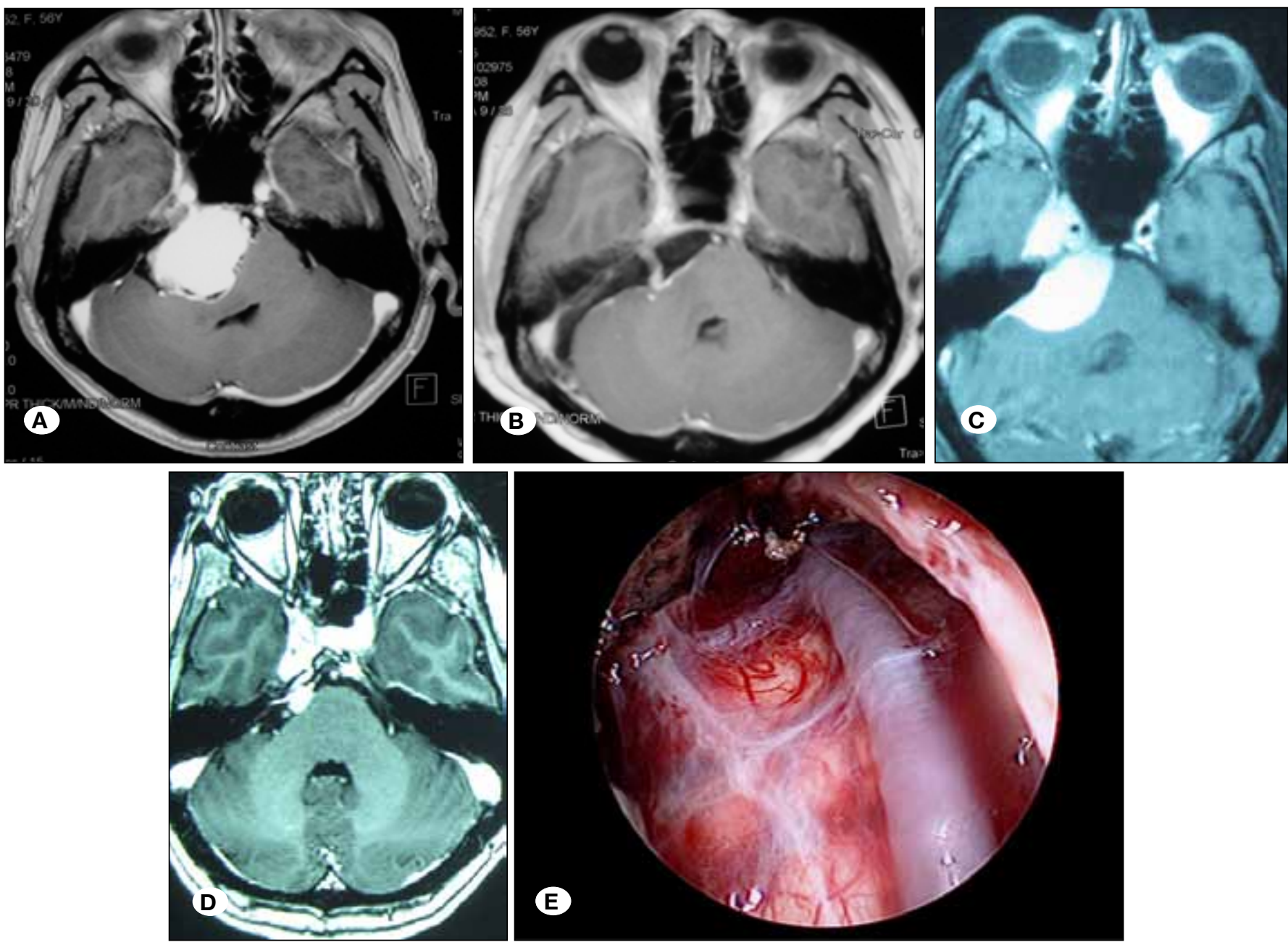

Figure 3: Examples of two petroclival meningiomas with two distinct management approaches. A) Preoperative post-gadolinium T1 MRI demonstrating a large petroclival meningioma in a young patient. Note that the tumor does not invade the cavernous sinus significantly, and given the patient's age, we elected to remove this tumor through a keyhole retrosigmoid approach to attempt a gross total resection as seen in (B). C) Post-contrast MRI demonstrates a large petroclival meningioma in an older patient with brain stem compressive symptoms. Note that the tumor invades the cavernous sinus, and given the patient's age and co-morbidities, we decided that brain stem decompression alone was adequate. This decompression was performed via an endonasal approach, with good post-operative result (D). Intraoperative images shown in (E) demonstrate endoscopic anatomy from this procedure. 
Approach selection once again is influenced by pre-operative imaging and surgical intention. If the tumor is mostly midline, the major vessels are clearly separated from the capsule, there is significant brain stem compression and complete removal may not be the surgical goal, then we choose the EEA. Figure 3A-E demonstrates two examples of how we decide between the use of the transcranial route versus the EEA in specific cases.

\section{Limitations of the Present Study}

One limitation of our study is that there is no comparison group. However, given that we reserve transcranial approaches for the most difficult cases, it is unclear what purpose a comparison study would serve, as the complication rate would almost certainly be higher in the transcranial group. Relatedly, there is an inherent selection bias in this study as we believe that the endonasal approach is not the best approach for all meningiomas.

Some aspects of our endoscopic endonasal approaches are not practiced at by all groups, including our skull base reconstruction technique. While others have reported success with innovative methods, we have had few CSF leaks with our method (4\% in this series). That said, this work is not meant to explicitly advocate our reconstruction technique.

\section{CONCLUSION}

In this study, we present outcomes from a cohort of patients treated selectively with endonasal endoscopic meningioma surgery. Judicious patient selection and clearly defined goals of surgery are critical to the effectiveness of this resection strategy. We believe that these results show that, while not appropriate for all midline cranial base meningiomas, very low rates of morbidity can be achieved in carefully selected patients, thus avoiding brain manipulation involved in transcranial surgery.

\section{ACKNOWLEDGMENT}

$\mathrm{Dr}$ Teo is a consultant for Aesculap. The other authors declare that they are not involved in any relationships with companies that make products related to this study, and have no funding sources relevant to this work to acknowledge.

\section{REFERENCES}

1. Cappabianca P, Cavallo LM, Esposito F, de Divitiis E: Endonasal approaches to the cavernous sinus. In: Anand V, Schwartz T (ed), Practical Endoscopic Skull Base Surgery. San Diego, CA: Plural Publishing, 2007: 177-190

2. Ceylan S, Koc K, Anik I: Endoscopic endonasal transsphenoidal approach for pituitary adenomas invading the cavernous sinus. J Neurosurg 112: 99-107, 2010

3. Ciric I, Ragin A, Baumgartner C, Pierce D: Complications of transsphenoidal surgery: Results of a national survey, review of the literature, and personal experience. Neurosurgery 40: 225-236, 1997
4. de Divitiis E, Cavallo LM, Cappabianca P, Esposito F: Extended endoscopic endonasal transsphenoidal approach for the removal of suprasellar tumors: Part 2. Neurosurgery 60: 46-58, 2007

5. de Divitiis E, Cavallo LM, Esposito F, Stella L, Messina A: Extended endoscopic transsphenoidal approach for tuberculum sellae meningiomas. Neurosurgery 61: 229-237, 2007

6. de Divitiis E, Esposito F, Cappabianca P, Cavallo LM, de Divitiis O, Esposito I: Endoscopic transnasal resection of anterior cranial fossa meningiomas. Neurosurg Focus 25: E8, 2008

7. Dehdashti AR, Ganna A, Witterick I, Gentili F: Expanded endoscopic endonasal approach for anterior cranial base and suprasellar lesions: Indications and limitations. Neurosurgery 64: 677-687, 2009

8. El-Sayed IH, Roediger FC, Goldberg AN, Parsa AT, McDermott MW: Endoscopic reconstruction of skull base defects with the nasal septal flap. Skull Base 18: 385-394, 2008

9. Frank G, Pasquini E: Endoscopic endonasal cavernous sinus surgery, with special reference to pituitary adenomas. Front Horm Res 34: 64-82, 2006

10. Gardner PA, Kassam AB, Thomas A, Snyderman $\mathrm{CH}$, Carrau $\mathrm{RL}$, Mintz AH, Prevedello DM: Endoscopic endonasal resection of anterior cranial base meningiomas. Neurosurgery 63: 36-52, 2008

11. Hadad G, Bassagasteguy L, Carrau RL, Mataza JC, Kassam A, Snyderman $\mathrm{CH}$, Mintz A: A novel reconstructive technique after endoscopic expanded endonasal approaches: Vascular pedicle nasoseptal flap. Laryngoscope 116: 1882-1886, 2006

12. Harvey RJ, Nogueira JF, Schlosser RJ, Patel SJ, Vellutini E, Stamm AC: Closure of large skull base defects after endoscopic transnasal craniotomy. J Neurosurg 111:371-379, 2009

13. Hayhurst $C$, Teo $C$ : Tuberculum sella meningioma. Otolaryngol Clin North Am 44: 953-963, viii-ix, 2011

14. Jho HD: Endoscopic transsphenoidal surgery. J Neurooncol 54: 187-195, 2001

15. Kaptain GJ, Vincent DA, Sheehan JP, Laws ER Jr: Transsphenoidal approaches for the extracapsular resection of midline suprasellar and anterior cranial base lesions. Neurosurgery 49: 94-100, 2001

16. Kassam AB, Prevedello DM, Carrau RL, Snyderman $C H$, Thomas A, Gardner P, Zanation A, Duz B, Stefko ST, Byers $\mathrm{K}$, Horowitz MB: Endoscopic endonasal skull base surgery: Analysis of complications in the authors' initial 800 patients. $J$ Neurosurg 114: 1544-1568, 2011

17. Kassam AB, Thomas A, Carrau RL, Snyderman $C H$, Vescan A, Prevedello D, Mintz A, Gardner P: Endoscopic reconstruction of the cranial base using a pedicled nasoseptal flap. Neurosurgery 63: ONS 44-52, 2008

18. Kitano M, Taneda M: Extended transsphenoidal approach with submucosal posterior ethmoidectomy for parasellar tumors. J Neurosurg 94: 999-1004, 2001 
19. Koutourousiou M, Fernandez-Miranda JC, Stefko ST, Wang EW, Snyderman $\mathrm{CH}$, Gardner PA: Endoscopic endonasal surgery for suprasellar meningiomas: Experience with 75 patients. J Neurosurg 120: 1326-1339, 2014

20. Laufer I, Anand VK, Schwartz TH: Endoscopic, endonasal extended transsphenoidal, transplanum transtuberculum approach for resection of suprasellar lesions. J Neurosurg 106: 400-406, 2007

21. Schwartz TH, Fraser JF, Brown S, Tabaee A, Kacker A, Anand VK: Endoscopic cranial base surgery: Classification of operative approaches. Neurosurgery 62: 991-1002, 2008
22. Sughrue ME, Rutkowski MJ, Aranda D, Barani IJ, McDermott MW, Parsa AT: Factors affecting outcome following treatment of patients with cavernous sinus meningiomas. J Neurosurg 113: 1087-1092, 2010

23. Van Gompel JJ, Frank G, Pasquini E, Zoli M, Hoover J, Lanzino G: Expanded endonasal endoscopic resection of anterior fossa meningiomas: Report of 13 cases and meta-analysis of the literature. Neurosurg Focus 30: E15, 2011 